\title{
The Racial Identity and Cultural Orientation of Lumbee American Indian High School Students
}

\author{
ALFRED BRYANT JR. \\ University of North Carolina at Pembroke \\ TERESA D. LAFROMBOISE \\ Stanford University
}

\begin{abstract}
The uncertain and complex lineage of the Lumbee American Indian tribe has made the issue of identity of prime concern. The cultural identification, racial identification, bicultural competence, and perceived school environment for 103 Lumbee Indian high school students were examined in this study. Higher self-ratings on American Indian cultural competence and American Indian cultural identification than on White cultural competence and White cultural identification were found, and $\mathrm{t}$-test comparisons revealed no gender differences on responses to the instruments. Analysis of variance was conducted to assess whether differences in perceived school environment could be attributed to cultural orientation. Rather than appearing assimilated, this generation of Lumbees tends to exhibit J. E. Helms's (1995b) Internalization identity status and an American Indian cultural orientation.

Keywords: racial identity, cultural orientation, biculturalism, Lumbee American Indian
\end{abstract}

Approximately 45,000 strong, members of the Lumbee American Indian tribe reside predominantly in Robeson County, North Carolina. The majority live in or around the small town of Pembroke, but they have also established communities in surrounding counties as well as several other states within the United States. Lumbee American Indians have been a proud and independent people who have established their own viable community. According to Evans (1995), the forbearers of the Lumbee were speaking

- Alfred Bryant Jr., School of Education, University of North Carolina at Pembroke; Teresa D. LaFromboise, Counseling Psychology Program, School of Education, Stanford University.

Correspondence concerning this article should be addressed to Teresa D. LaFromboise, School of Education, Stanford University, 485 Lasuen Mall, Stanford, CA 94305-3096. E-mail: lafrom@stanford.edu 
English as early as the 18th century, giving rise to the theory that Lumbees are actually descendants of Sir Walter Raleigh's lost colony of Roanoke Island (Dial, 1993; Gaillard, 1998). "They have never been placed on reservations, nor have they been wards of either the state or the federal government" (Dial \& Eliades, 1975, p. xiv). Consequently, Lumbee American Indians have a unique and controversial history and status.

They know they are members of an American Indian tribe, but their tribal history is not formally documented. Therefore Lumbee American Indians cannot avoid the issue of identity. It is not that they are trying to regain their Indian identity; it is simply that the outside world, both the American Indian community and federal government, remains absorbed in trying to classify them and, consequently, refrains from acknowledging their identity (Woods, 2001). "Our children and our people experience "identity crisis,' not because we do not know who we are and what we are, but because of the lack of affirmation of our identity by external forces and recognition of our native birthright" (R. D. Woods, personal communication, June 1, 2004).

This lack of historical confirmation leaves them without the federal recognition that most other American Indian tribes across the United States possess. In fact, they have been criticized by federally recognized tribes as having too open an enrollment policy in determining tribal membership (Jaimes, 1995). And, as Snipp (1997) has noted, "Disputed claims to group membership can become vitriolic when these claims are linked to eligibility requirements in the distribution of scarce resources" (p. 675). Lumbees are a state-recognized tribe but, without federal recognition, they are viewed by the government as an ambiguous entity (Sider, 1993). Because of this attribution, some may tend to view themselves as such.

Given their unique history, Lumbee American Indians are often viewed as an acculturated tribal people (Maynor, 1996). They tend to possess different religious practices, social practices, customs, and beliefs than many federally recognized American Indian tribes. They do not know their native language as do some tribes. Lumbees also often look different from what an American Indian is too often thought to look like. There is much variety in the physical characteristics within the tribe. Hair color and skin complexion vary across the spectrum.

Although they do not possess the same cultural traits as other tribes, many are common. They make an effort to discover many of the lost arts, crafts, and practices of their American Indian ancestors. Because their traditional cultural heritage is a major influence in their lives, many Lumbees remain attached to nature and the spiritual world. Religious values and teachings greatly influence the lives of these individuals. The majority practice the religion they were taught by their parents and grandparents, which is the Southern Baptist faith. As in other tribal groups, Lumbees rely on the cultural teachings of their elders to guide their actions and reactions. These cultural teachings are most often in the form of oral history.

However, Lumbee American Indians face the continuing struggle of defining their identity. Where other tribes have welldocumented and precise histories, the Lumbee history is uncertain. It appears likely that the people now called Lumbees are made up of a combination of indigenous American Indians, joined by early European settlers and later by others seeking refuge from social chaos, oppression, or slavery (see Forbes, 1990, for a discussion of RedBlack Indians). This complex lineage and legacy have created identity crises among the Lumbee people because they are not readily accepted by some American Indian tribes owing to the questions of origin, which remain unanswered.

To be a Lumbee is to be cloaked in the myths and uncertainties of the past, to find your pride in Indianness being challenged and denigrated. Most important, it is to find some of one's basic rights as an American and a human being restricted if not denied. Indeed, shorn of all frills, the history of the Lumbees is a history of struggle. The total 
story is one of struggle to gain acceptance as Indians, to escape the emasculating effects of discriminatory laws and to join the mainstream of society as first-class citizens. The Lumbees, by whatever name they were variously called through the centuries, have always known themselves as Indians. They have been known, recognized, and mistreated as Indians by their surrounding white communities. Theirs has been a centuries-old struggle indeed. But while the struggle is certainly not over, the Indian people are meeting the challenges they face, with considerable success. (Dial \& Eliades, 1975, p. xiv)

With this said, it is evident that Lumbee youths are culturally different in many respects from American Indian youths of other tribes (Sider, 2003). For instance, because of early and continuous contact with White society, Lumbees naturally experience higher degrees of acculturation than most reservation tribes. When Lumbees enter high school they are often fluent in the beliefs and practices of the dominant culture, and most are capable of leaving the community to work or attend college because of their acculturative status. This further delineates them from youths from other tribes who are not as inclined to leave their home area. The lower levels of acculturation experienced by youths from some tribes represent a challenge to their educational success outside of the reservation.

Although little research has been done with the American Indian adolescent in general (Bee-Gates, Howard-Pitney, LaFromboise, \& Rowe, 1996), even less attention has been directed toward their racial or ethnic identity (Martinez \& Dukes, 1997; Mihesuah, 1999). Given the uncertain status of Lumbee youths within the American Indian community and the dominant White society, several questions became the focus of this investigation: How can the racial identity of Lumbee Indian youths be described; what is the cultural orientation of Lumbee youths; and does the cultural orientation of Lumbee students affect their perception of the school environment?
Method

\section{Participants}

Lumbee American Indian high school students were recruited from six high schools in Robeson County in southeastern North Carolina. The American Indian high school youth development counselor employed by the Indian education program of each school was trained to carry out the data collection and to explain the purpose of the project. Counselors administered the survey packets in a group setting during a monthly Indian education meeting at each of the high schools. Approximately $75 \%$ of the Lumbee students in these schools actively participate in the Indian education program.

Survey packets contained a cover letter/ consent statement, a demographic data sheet, and (a) the People of Color Racial Identity Attitude Scale, plus (b) the Living in Two Worlds Survey, Cultural Identification Scale, and the school environment questions. The order of $\mathrm{a}$ and $\mathrm{b}$ was rotated to counterbalance the presentation of materials. Participation was voluntary with no incentives offered, but anonymity was assured. Over $95 \%$ of the students attending participated.

The mean age of the sample was 17.3 years, ranging from 14 to 19 years. Of the 103 participants, 62 were female and 41 were male. Although 6 participants did not indicate their grade level, 10 were in the 10 th grade, 22 in the 11 th grade, and 65 in the 12th grade. The typical socioeconomic status in this community would be considered below average, and the median family annual income was estimated at $\$ 12,400$ (U.S. Census Bureau, 2002).

\section{Instruments}

The People of Color Racial Identity Attitude Scale (POCRIAS; Helms, 1995a) was developed to provide a measure of the racial identity attitudes, due to their perceived shared experiences with racial oppression, 
of those people whose ancestry appears to be Asian, African, Latino/Latina, or Native American in the United States. According to Helms's people of color racial identity theory (Helms, 1995b), individuals' racial identity attitudes can be described by Conformity (conformance to racial status quo; devalues own racial group), Dissonance (confusion concerning own racial group), Immersion (idealization and psychological identification with own racial group), and Internalization (integration of commitment to own group and ability to respond objectively to positive aspects of Whites).

The POCRIAS contains 50 statements divided into four subscales based on the statuses noted above. Participants are asked to respond to each item using a Likert scale $(1=$ strongly agree to $5=$ strongly disagree $)$. Higher scores on each of the four subscales indicate stronger levels of the relevant racial identity attitudes. Alpha reliability coefficients found in this investigation were as follows: Conformity, .61; Dissonance, .73; Immersion, .76; and Internalization, .77, values similar to those reported by Kohatsu (1992), Bryant and Baker (2003), and Miville (1996). Alvarez (1996) and Canabal (1995) also reported interscale correlations ranging from -.34 to .53 and -.45 to .37 , respectively. J. E. Helms (personal communication, January 16, 1998) has endorsed the content validity of the POCRIAS, although empirical evidence for validity is not yet available.

The Living in Two Worlds Survey (LTWS; LaFromboise, 1999) was developed to measure the cultural competence of American Indian adolescents in both the dominant and American Indian society. It contains 50 items divided into two scales, American Indian and White American. The items are grouped under the following topics: Friendship, Communication, Community Membership, Support, and Cultural Knowledge. Participants are asked to respond in terms of how well each item describes or applies to them using a Likert format $(\mathrm{A}=$ very to $\mathrm{D}=$ not at all $)$. Higher scores on each scale indicate greater competence in that society.

Alpha reliability coefficients for this sample were American Indian, .83, and White American, .94, values similar to those reported by LaFromboise (1999). The interscale correlation for this study was .02 . Because of this independent relationship, scores from each scale can be divided into high and low groups, thus providing a matrix of cultural orientation: high Indian/ high White; high Indian/low White; low Indian/high White; and low Indian/low White.

The Cultural Identification Scale (CIS; Oetting \& Beauvais, 1991) contains four items that the authors identify as sufficient in measuring the cultural identification of minority youths when posed separately to refer to White American life and the minority culture(s) meaningful to the respondents. We used these items relating to both White American and Indian ways, thus creating two 4-item orthogonal scales. Participants are asked to respond to choices presented in a Likert format $(\mathrm{A}=a$ lot to $\mathrm{D}=$ not at all). Higher scores on each scale indicate greater identification with that culture. The authors report that these scales have reliabilities in the high $.80 \mathrm{~s}$, and in this investigation, indeed, we found Cronbach's alpha reliabilities of .91 and .87 for the White and Indian scales, respectively. (The modification of this scale by Moran, Fleming, Somervell, and Manson did not appear until late in 1999, by which time our data had been collected.) Oetting and Beauvais have amassed considerable evidence establishing a link between cultural identification and family functioning, self-esteem, school adjustment, and drug use.

School environment was measured by the four items that compose the section "Youth Perceptions of Negative Treatment Due to Race" from a research instrument concerned with perceived school environment developed by Roeser, Eccles, and Sameroff (1998). An item example is "How often do you feel that teachers discourage you from taking certain classes because of 
your race?" Four response choices were offered, ranging from a lot to not at all. Because of this limited scope, no psychometric data are available.

\section{Results}

As a result of $t$ tests, no gender differences were discovered in the scores on the POCRIAS, LTWS, CIS, or the school items. The mean item score and standard deviation for each scale of the POCRIAS are shown in Table 1. Internalization scores were highest, followed by Immersion scores, Dissonance scores, and Conformity scores. All differences in scores between scales were significant at the .05 level or better.

The mean item scores on the LTWS were $3.6(S D=0.28)$ and $3.0(S D=0.59)$ for the American Indian and White American scales, respectively, a statistically significant difference, $t(102)=9.31, p<.001$. Scores on the American Indian and White American cultural identification scales were 3.1 $(S D=0.72)$ and $2.5(S D=0.94)$, respectively, which were also significantly different, $t(102)=5.88, p<.001$.

Scores on the American Indian and White American scales of the LTW were divided into equal thirds of high, medium, and low scores and plotted on horizontal and vertical axes. The scores of students in the corners of the resulting nine-cell matrix (representing high Indian/high White,

TABLE 1 Mean Item Scores, Standard Deviations, and Reliability Estimates for POCRIAS Subscales

\begin{tabular}{lccc}
\hline Subscale & $M$ & $S D$ & $r$ \\
\hline Internalization & 4.29 & .55 & $.77^{*}$ \\
Immersion & 2.98 & .57 & $.76^{*}$ \\
Dissonance & 2.54 & .52 & $.73^{*}$ \\
Conformity & 1.84 & .44 & $.61^{*}$ \\
\hline
\end{tabular}

Note. POCRIAS $=$ The People of Color Racial Identity Attitude Scale.

$* p<.05$. high Indian/low White, low Indian/high White, and low Indian/low White) were analyzed by analysis of variance to determine whether there were differences in perceived school environment that could be attributed to these cultural orientations. No suggestion of differences was discovered, $F(3,42)=$ $.413, p<.74$.

The correlations of scores on all scales administered were also examined. American Indian and White culture and American Indian and White identification appear totally independent (.02 and .04, respectively), thus supporting the conceptual integrity of the measures. Also noteworthy is that Internalization appears more closely related to a bicultural outlook than White or American Indian orientations and that perceived school environment shows no relationship with any other variable.

\section{Discussion}

The results of this investigation support the view that Lumbee American Indian high school students develop a strong sense of American Indian identity. The findings on the POCRIAS indicate that the Lumbee students in this study are best characterized by the Internalization racial identity status. This suggests they possess a positive American Indian racial identity and also have the ability to acknowledge the positive aspects of White society. They appear less characterized by the Immersion status, indicating a moderate amount of physical and psychological withdrawal into the Lumbee American Indian racial group and culture. The Dissonance and Conformity statuses were least representative of these students, thus suggesting that they are likely to experience a minimal degree of confusion or disorientation in regard to their identity when racial dynamics are encountered and are quite aware of the significant impact that race has in their lives without accepting the racial status quo. 
These findings appear to be confirmed by the data from the measures of cultural orientation and cultural identification. The Lumbee students scored significantly higher on the American Indian scale than on the White American scale of the LTWS. This suggests that their primary cultural orientation is toward identification with the Lumbee society, which is further supported by the results from the CIS. However, their orientation or identification with White American society appears to be functionally strong. Thus, the picture that emerges is that of biculturally competent high school students-who understand White American society but who have allegiance to Lumbee Indian society. Of course, biculturalism was operationalized in the questionnaire and may be reductionistic. However, it did include many concepts thought to be significant, such as friendship patterns, ease in communicating, identification with community, and perceived source of support.

Certain other limitations of this study are apparent and could affect the interpretation of the data reported here. For instance, it was observed that a normal distribution was not attained on several scales, most noticeably on the American Indian scale of the LTWS. Compared with a national sample of 413 American Indian students (LaFromboise, 1999), Lumbee students scored .4 higher on the American Indian scale and .2 higher on the White American scale, a difference that may be artifactual but is statistically significant. With the scores strongly negatively skewed, a ceiling effect is encountered that prevents distinguishing among students with bunched high scores. Although we still suspect that cultural orientation may be related to the perceived school environment, the skewed distributions and resulting ceiling effect may have obscured this relationship.

Observation of the scatter plots of scores on the American Indian and White American scales of the LTWS revealed that, compared with the national sample, the pattern was distinguished by the almost total lack of low American Indian scores. The question then arises as to the possible causes for the idiosyncratic response pattern of the Lumbee students. On the one hand, the scores could accurately represent an intense attachment to the local historic cohesiveness. This effect could have been enhanced because Lysne and Levy (1997) have shown that Native American Indian high school students attending a school with a predominantly American Indian student body demonstrate stronger ethnic identity than those attending a predominantly White institution. On the other hand, the lack of virtually any low American Indian scores could be the result of the procedural arrangements. The environmental press in a Native American Student Association meeting with the materials administered by the American Indian youth development counselor may have effectively suppressed more negative responses to the American Indian items.

This problem notwithstanding, the results of this investigation provide evidence that Lumbee American Indian high school students in the Robeson County community in North Carolina appear to recognize and accept their cultural heritage. Regardless of their undocumented tribal history, the lack of a Native American Indian language, and the differences that set them apart from other American Indian tribes, Lumbee students today tend to exhibit the Internalization racial identity status and an American Indian cultural identification. These findings support the claim that ancestry and identity need to be decoupled (Mihesuah, 1999).

Because the Lumbee have been questioned as legitimate native people, it is especially significant that the most recent generation demonstrates a strong identification with Indianness. Clinicians and educators who interact with Lumbee youths need to be aware that, despite their long history of oppression, rather than becoming culturally assimilated, the young generation of Lumbees today appear to be strengthening their unique cultural orientation. 


\section{References}

Alvarez, A. (1996). Asian American racial identity: An examination of world views and racial adjustment (Doctoral dissertation, University of Maryland, College Park, 1996). Dissertation Abstracts International, 57, Z6554.

Bee-Gates, D., Howard-Pitney, B., LaFromboise, T., \& Rowe, W. (1996). Help-seeking behavior of Native American Indian high school students. Professional Psychology: Research and Practice, 27, 495-499.

Bryant, A., Jr., \& Baker, S. (2003). The feasibility of constructing profiles of Native Americans from the People of Color Racial Identity Attitude Scale: A brief report. Measurement and Evaluation in Counseling and Development, 36(1), 2-8.

Canabal, I. (1995). Latino group identities, collective and personal self-esteem (Doctoral dissertation, University of Maryland, College Park, 1995). Dissertation Abstracts International, 56, Z4574.

Dial, A. L. (1993). The Lumbee. New York: Chelsea House.

Dial, A., \& Eliades, D. K. (1975). The only land I know: A history of the Lumbee Indians. San Francisco: Indian Historian Press.

Evans, W. M. (1995). To die game: The story of the Lowry band, Indian guerrillas of Reconstruction. Syracuse, NY: Syracuse University Press.

Forbes, J. D. (1990). The manipulation of race, caste, and identity. Journal of Ethnic Studies, $17(4), 1-51$.

Gaillard, F. (1998). As long as the waters flow: Native Americans in the South and the East. WinstonSalem, NC: John F. Blair.

Helms, J. E. (1995a). The People of Color (POC) Racial Identity Attitude Scale. Unpublished manuscript, University of Maryland, College Park.

Helms, J. E. (1995b). An update of Helms's White and people of color racial identity models. In J. G. Ponterotto, J. M. Casas, L. A. Suzuki, \& C. M. Alexander (Eds.), Handbook of multicultural counseling (pp. 181-198). Thousand Oaks, CA: Sage.

Jaimes, M. A. (1995). Some kind of Indian: On race, eugenics, and mixed-bloods. In N. Zack (Ed.), American mixed race: The culture of micro diversity (pp. 133-153). Lanham, MD: Rowman \& Littlefield.

Kohatsu, E. L. (1992). The effects of racial identity and acculturation on anxiety, assertiveness, and ascribed identity among Asian American college students (Doctoral dissertation, University of Maryland, College Park, 1992). Dissertation Abstracts International, 54, Z1102.

LaFromboise, T. D. (1999). [The Living in Two Worlds Survey]. Unpublished test instrument, Stanford University, Stanford, CA.

Lysne, M., \& Levy, G. D. (1997). Differences in ethnic identity in Native American adolescents as a function of school context. Journal of Adolescent Research, 12, 372-388.

Martinez, R. O., \& Dukes, R. L. (1997). The effects of ethnic identity, ethnicity, and gender on adolescent well-being. Journal of Youth and Adolescence, 26, 503-516.

Maynor, M. (Producer). (1996). Real Indian [Motion picture]. New York: Women Make Movies.

Mihesuah, D. (1999). American Indian identities: Issues of individual choice and development. In D. Champaign (Ed.), Contemporary Native American cultural issues (pp. 13-37). Walnut Creek, CA: Alta Mira Press.

Miville, M. L. (1996). Exploring relationships of cultural, gender, and personal identity among Latinos and Latinas (Doctoral dissertation, University of Maryland, College Park, 1996). Dissertation Abstracts International, 58, Z458.

Moran, J. R., Fleming, C. M., Somervell, P., \& Manson, S. M. (1999). Measuring bicultural identity among American Indian adolescents: A factor analytic study. Journal of Adolescent Research, 14, 405-426.

Oetting, E. R., \& Beauvais, F. (1990-1991). Orthogonal cultural orientation theory: The cultural identification of minority adolescents. International Journal of the Addictions, 25, $655-685$.

Roeser, R. W., Eccles, J. S., \& Sameroff, A. J. (1998). Academic and emotional functioning in early adolescence: Longitudinal relations, patterns, and prediction by experience in middle school. Development and Psychopathology, 10, 321-352.

Sider, G. M. (1993). Lumbee Indian histories: Race, 
ethnicity and Indian identity in the southern United States. New York: Cambridge University Press.

Sider, G. M. (2003). Living Indian histories: Lumbee and Tuscarora people in North Carolina. Chapel Hill: University of North Carolina Press.

Snipp, C. M. (1997). Some observations about racial boundaries and the experiences of
American Indians. Ethnic and Racial Studies, 20, 321-352.

U.S. Census Bureau. (2002). The American Indian and Alaska Native population: 2000. Washington, DC: Author.

Woods, R. D. (2001). Growing up Red: The Lumbee experience. Unpublished doctoral dissertation, University of North Carolina, Chapel Hill.

\section{Wanted: Old APA Journals!}

APA is continuing its efforts to digitize older journal issues for the PsycARTICLES database. Thanks to many generous donors, we have made great strides, but we still need many issues, particularly those published in the 1950 s and earlier.

If you have a collection of older journals and are interested in making a donation, please e-mail journals@apa.org or visit http://www.apa.org/journals/donations.html for an up-todate list of the issues we are seeking. 